\title{
DÜBLIN
}

Technological University Dublin

ARROW@TU Dublin

\section{Risk register and risk intelligence: the challenge of operational risks in the energy sector}

\author{
Maria Chiara Leva \\ Technological University Dublin, maria.leva@tudublin.ie \\ B. McAleer \\ ESB Generation, Dublin \\ M. Rocke \\ ESB Generation, Dublin
}

See next page for additional authors

Follow this and additional works at: https://arrow.tudublin.ie/schfsehcon

Part of the Occupational Health and Industrial Hygiene Commons, and the Other Public Health Commons

\section{Recommended Citation}

Leva, Maria \& McAleer, B \& Rocke, Michael \& Brogan, D. (2017). Risk register and risk intelligence: The challenge of operational risks in the energy sector. 267-267. 10.1201/9781315210469-236.

This Conference Paper is brought to you for free and open access by the School of Food Science and Environmental Health at ARROW@TU Dublin. It has been accepted for inclusion in Conference papers by an authorized administrator of ARROW@TU Dublin. For more information, please contact arrow.admin@tudublin.ie, aisling.coyne@tudublin.ie,gerard.connolly@tudublin.ie.

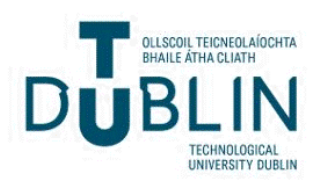


Authors

Maria Chiara Leva, B. McAleer, M. Rocke, and D. Brogan

This conference paper is available at ARROW@TU Dublin: https://arrow.tudublin.ie/schfsehcon/33 
See discussions, stats, and author profiles for this publication at: https://www.researchgate.net/publication/317394786

\section{Risk register and risk intelligence: The challenge of operational risks in the energy sector}

Conference Paper · June 2017

DOI: 10.1201/9781315210469-236

4 authors, including:

Maria Chiara Leva

Technological University Dublin - City Campus

113 PUBLICATIONS 535 CITATIONS

SEE PROFILE

Mymedis

5 PUBLICATIONS 43 CITATIONS

SEE PROFILE

Some of the authors of this publication are also working on these related projects:

laser fusion diagnostics View project 


\title{
Risk Register and Risk intelligence: the challenge of operational risks in the energy sector
}

\author{
M.C. Leva \\ Dublin Institute of Technology, Ireland \\ B. McAleer M.Rocke D. Brogan \\ ESB generation Dublin, Ireland
}

\begin{abstract}
This paper presents the needs and the challenges encountered in developing a company-wide risk register in the energy sector. The study presented comes from an electricity generation company and it was useful to indicate areas where the concept of risk registers could be extended to make better use of existing data and to support continuous improvement of risk management. Six key areas are discussed 1) aggregation of risks across the business, 2) supporting controls over mitigation measures, 3) improved estimation of event likelihood, 4) integrating with critical asset registers, 5) improving risk communication, and 6) linking with day-to-day operational practice. The paper concludes with a framework for placing risk registers at the heart of Process Safety.
\end{abstract}

\section{INTRODUCTIONS}

\subsection{Risk registers and their usage}

To develop risk Intelligence organizations need to continuously review and monitor their operational risks. The results of safety studies and/or the evidence of issues collected from operational experience must therefore be translated into a format that can be updated as new evidence becomes available from the operational reality, it needs to be analysed, reviewed and acted upon (Monferini et al. 2013). This helps to create an 'informed culture', defined by Reason (1997) as a culture in which both management and operators are informed of and knowledgeable about the factors that influence safety as a whole. When the available information is shared between all applicable levels of the organisation, a Common Operational Picture (COP) can be created as the basis for safe and reliable system operation (Kontogiannis et al., 2017). The risk register can definitely contribute to support a shared understanding, or COP of the top risks faced by an organization.

A risk register, should contain all analysed risks and should prioritise the areas that require managerial attention and typically contains information describing each risk, an assessment of the likelihood and consequences, a ranking according to a risk matrix, the risk owner, and information on the mitigations to be put in place (Filippin and Dreher, 2004). When populated with information on each risk, including risk ranking, the risk register can present the risk profile for different aspects of the organisation (Filippin and Dreher, 2004). When reviewed and updated over time, it can also present trends within the risk profile and focus management attention on the highest risk activities or facilities (Whipple and Pitblado, 2010). Risk registers are used in a variety of industries, including high hazard industries such as oil and gas (Hasle et al., 2009) and electricity generation (Leonard, 1995). They are typically used either to support safe operations or to support safe and efficient project management (e.g. De Zoysa and Russell, 2003). Cooke-Davies (2002) found that the adequacy with which a visible risk register was maintained was one of the key success factors for project management. Patterson and Neailey (2002) highlight the importance of the risk register and suggest that the benefit of a risk register is as a method to enable all stakeholders to "consciously evaluate and manage the risks as part of a decision making process". They also note the importance of the risk register in documenting the process of reducing risk and introducing mitigations. However, Kutsch and Hall (2010) warn of the danger of risk registers becoming 'tick-box' exercises when the owners and contributors do not have a real ability to influence the risks - the danger of irrelevance. Despite the clear importance of risk registers in the risk management process, there is very little guidance on their development and implementation (Dunovi et al., 2013). The Design Information Group at Bristol University found that $67 \%$ of the operators working in Engineering Design project, documented their risks on either a paper or computer-based risk register (Crossland et al 1998). However these were generally individual solutions, usually hosted locally suggesting the format of an individual risk register rather than a 
company-wide shared solution (Patterson and Neailey, 2002).

This paper describes how a company developed a solution shared across different types of stations and realities in an electricity generation company and how the results were used for Management Review decisions. The key objectives of the case study were:

- To develop a data structure able to support consistent hazard identification and risk rating across different sites;

- To develop equivalent severity and frequency scales for different loss types and for application across different business units, such as operations, maintenance, finance, HR etc.;

- To use the risk register to highlight key business risks to senior management;

- To use the risk register to gather information about mitigation measures in place and their effectiveness;

- To embed the risk register within a risk management process and share good practices across the company.

\section{KEY ELEMENS IN A RISK REGISTER}

\subsection{Risk register: the need}

Risk management during operations relies on the on-going identification, evaluation, and monitoring of risks with the potential to affect safety or performance. The organisation involved in this case study, had an existing process which relied on the plant managers from each station across the business reporting their 'Top 10' risks to a central risk manager who collated and analysed the full set for presentation to senior management. A number of issues were identified with this process, particularly:

-It was labour intensive;

-Not transparent to the stations reporting risks;

-Did not facilitate learning across the organisation;

-Not consistent in the reporting and rating of risks;

-Not comprehensive in the types of risks covered;

-Only updated quarterly;

-No ability to data-mine or trend the data.

This is why the company required the development of a single risk register for the purpose of supporting the identification and management of operational risks encompassing all business units into a single dynamic source. The risk register needed to include a process for communication and review of the top business risks and control measures by senior management at a defined frequency. Furthermore the need of the end users (stations) inputting their risks was also considered in terms of:

- possibility to share best practices or solutions with other stations/users having similar problems
- gather feedback form management about their risk and possible mitigation strategy coordinated centrally rather than locally

- use the risk register to support performance reporting against company objectives.

The case study was developed within a FP7 EU funded project on Total Safety Management called TOSCA (Leva et al. 2014). A series of workshops were coordinated with the energy company to involve all the key stakeholders and define a vision and action plan for the risk register (see Balfe et al. 2014 for more detail) the workshops were needed to address the need to develop a shared understanding of risk and hazard concepts and harmonize the differences between individual and corporate perspectives on risk. Risks may have different consequences depending on the viewpoint of an individual/group (Leva et al. 2012). For example, a transformer failure would have high consequences for an individual generation station as they cannot export the electricity generated. However, it is not necessarily an issue for the business as it can be compensated with another station, and can even be a benefit to those other stations that will receive a higher payment for exporting more electricity. These different perspectives must be reconciled by monetizing values of those risks and aggregating them at overall business level.

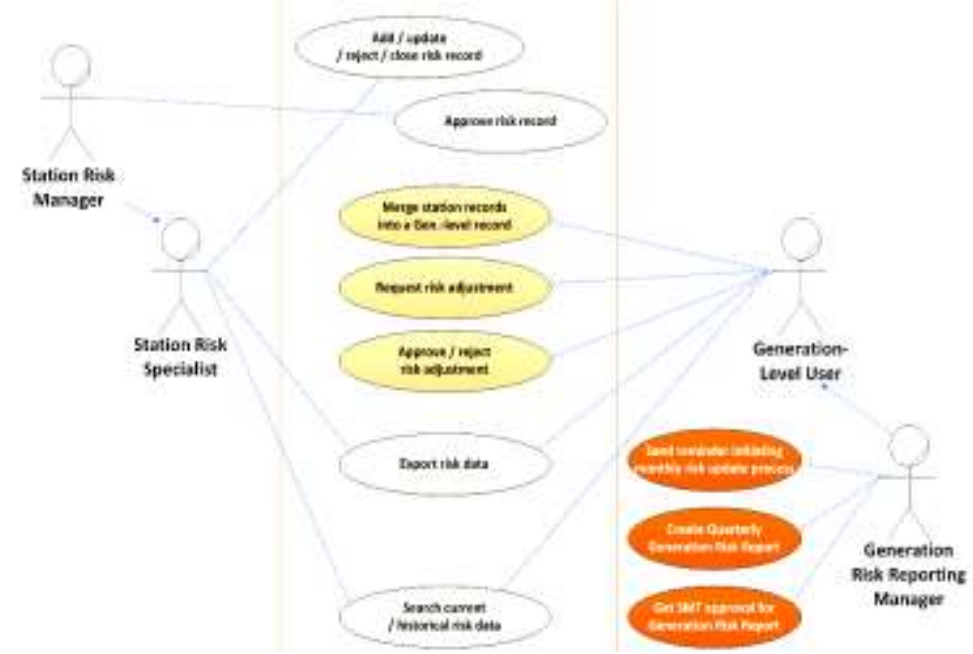

Figure 1. Use case diagram for Risk register

The workshops led to the definition of 10 high level requirements (Table 1), plus the supporting components of a risk matrix and associated loss and consequence tables. While Figure 1 reports the use case diagrams developed for the company involved. 
Table 1: High-level requirements for risk register

\begin{tabular}{|c|c|}
\hline ID & Description (High Level Requirement) \\
\hline HLR1 & $\begin{array}{l}\text { Create a comprehensive and consistent risk man- } \\
\text { agement process. }\end{array}$ \\
\hline HLR2 & $\begin{array}{l}\text { Reports/matrices shall provide an update of the risk } \\
\text { levels within the business at a particular moment } \\
\text { of time and take into account possible short term } \\
\text { emerging risks i.e. weather extremes, equipment } \\
\text { type faults, internal or external incident investiga- } \\
\text { tions, etc. }\end{array}$ \\
\hline HLR3 & $\begin{array}{l}\text { The risk management system shall ensure that all } \\
\text { potential hazards are identified and assessed. }\end{array}$ \\
\hline HLR4 & $\begin{array}{l}\text { The risk management system shall ensure that ade- } \\
\text { quate control measures are put in place. }\end{array}$ \\
\hline HLR5 & $\begin{array}{l}\text { The risk management system shall ensure that con- } \\
\text { trol measures remain effective in the management } \\
\text { of each risk. }\end{array}$ \\
\hline HLR6 & $\begin{array}{l}\text { All risk information shall be held in a single risk } \\
\text { register which encompasses all business risks into a } \\
\text { single dynamic source. }\end{array}$ \\
\hline HLR7 & Periodic hazards and risk reviews to be carried out. \\
\hline HLR8 & $\begin{array}{l}\text { All hazards shall be identified, and periodic hazards } \\
\text { and risk reviews shall be carried out. }\end{array}$ \\
\hline HLR9 & $\begin{array}{l}\text { Key performance indicators shall be developed to en- } \\
\text { sure that the key hazards have been identified and } \\
\text { assessed, that all business risks are reviewed, and } \\
\text { that effective control measures are in place }\end{array}$ \\
\hline HLR10 & $\begin{array}{l}\text { The system shall be fully aligned to the company's } \\
\text { strategy, with strong and positive management lead- } \\
\text { ership to ensure that the business risks are under- } \\
\text { stood from the board room to the control room, with } \\
\text { real time risk management decision making and a } \\
\text { comprehensive risk assessment process. }\end{array}$ \\
\hline HLR11 & $\begin{array}{l}\text { A single company procedure for measurement and } \\
\text { reporting of risk clearly defined, understood and uti- } \\
\text { lised, (fundamental requirement of Process Safety). }\end{array}$ \\
\hline
\end{tabular}

\section{THE INTERIM DEVELOPMENT AND OUTCOMES}

\subsection{Summary of key components and their use}

There are some key components that are necessary to enable the management of risk notwithstanding the variety format risk registers may take. First is the description of the risk, and a unique identification number to facilitate tracking. A concise description is necessary to allow users and reviewers to understand what is being documented. Then a more detailed description can be provided for those that have a long history. Each risk must have an indication of its priority, in the form of a risk ranking. Risk rankings are calculated from the product of the severity and likelihood of the risk. The calculation may be more or less sophisticated, depending on the data available. Last but not least the actions required to improve or manage a risk should be documented, along with the overall risk owner who is responsible for ensuring progress of the risk against the planned timeline. The risk is responsible for ensuring overall progress.

Additional components have also been incorporated into the risk register, including documentation of existing controls, the risk status (e.g. open, closed, increasing, decreasing, etc.) and the type of risk and associated losses (e.g. safety, financial, reputational, legal, etc.), and the target risk level.

To facilitate risk evaluation, the risk register needed to be supported by a robust risk matrix and associated severity and likelihood scales. Different processes and parts of the organisation were already using matrices and scales, and in order to apply a companywide risk register, these needed to be aligned for consistency.

\subsubsection{The adopted Risk Matrix}

The risk matrix used in the register is a key component, it serves the purpose of providing the basis for ranking but also of the estimation for the categories according to which risk aggregation across station is going to be performed. Risk matrices are very popular but should be used with caution, and with careful explanations of embedded judgments (Cox 2008). The likelihood and severity categorizations (and therefore the risk ratings) require subjective interpretation, and different users may obtain different ratings of the same quantitative risks; According to Cox (2008) "quantitative risk" is defined as the product of a points coordinates when the axes are interpreted quantitatively, for example, frequency $\times$ severity. The risk Matrix adopted for the Risk register it's there to provide a rough discrete (ordered categorical) approximation to a more detailed, but not readily available underlying quantitative relation between likelihood and severity of scenarios (Risk= probability $\times$ consequence). Cox (2008) suggests that such an intuitive interpretation of the risk matrix as an approximation to an underlying quantitative model can only be sustained if the risk matrix, at a minimum, "discriminate reliably between very high and very low risks, so that it can be used as an effective screening tool to focus risk management attention and resources". This requirement is the "principle of weak consistency between the ordered categorization of risks provided by the matrix and the ranking of risks by an underlying quantitative formula"(Cox 2008). If this principle is respected all risks in the top qualitative category are quantitatively larger than all risks in the lowest qualitative category, and the risk matrix can discriminate reliably between at least some risks (Cox 2008). So it can be used as screening tool, which in the risk register is the main practical uses of the adopted risk matrix.

The $5 \times 5$ risk exposure matrix categorises risks as:

- Red (14-20); Unacceptable risk. Detailed action plan required to reduce to Medium 
- Orange (12-14); Apply immediate controls to reduce

- Yellow (6-10); Apply judgment: Specify mitigation responsibility and plan mitigation to reduce to Low

- Green (1-5); Acceptable risk: Monitor and manage by routine procedures to minimise or close off the risk.

The use of four categories matches industry common practice.

\subsubsection{Hazard Categories}

The risk register should monitor technical and non-technical hazards in order to fully represent potential risks. In this case, ISO 17776 in combination with an analysis of the hazards and risks already captured within the company was used to provide a framework of hazards within the risk register as reported in Table 2. This allows the company to systematically review hazard category and modify the classification system for new and emerging hazards after during the testing period and after if needed.

\section{Table 2: Hazard categories used}

\begin{tabular}{|c|c|}
\hline Category & Examples \\
\hline Technical & $\begin{array}{l}\text { Specific hazards relating to equipment - e.g. turbine: mechan- } \\
\text { ical , vibration, aging, pressure, etc.; }\end{array}$ \\
\hline Process & $\begin{array}{l}\text { Hazards relating to the process, e.g. leaks, explosive or } \\
\text { flammable materials, dust emissions, etc. }\end{array}$ \\
\hline $\begin{array}{l}\text { Work Activi- } \\
\text { ties }\end{array}$ & $\begin{array}{l}\text { - Hazardous activities, e.g. working at height, working with ve- } \\
\text { hicles, lone working, working over water, }\end{array}$ \\
\hline $\begin{array}{l}\text { Work Envi- } \\
\text { ronment }\end{array}$ & $\begin{array}{l}\text { - Hazards relating to the physical plant, e.g. ground conditions } \\
\text { (slips, trips and falls), sharp surfaces, hot/cold surfaces, con- } \\
\text { fined spaces, etc. }\end{array}$ \\
\hline External & $\begin{array}{l}\text { All external hazards, including natural hazards (e.g. seismic } \\
\text { activity, adverse weather), external accidents (adjacent } \\
\text { plants, aircraft), terrorism, etc. }\end{array}$ \\
\hline Behavioural & $\begin{array}{l}\text { Hazards resulting from inappropriate behaviours, e.g. intoxica- } \\
\text { tion, interference with safety mechanisms }\end{array}$ \\
\hline $\begin{array}{l}\text { Organisa- } \\
\text { tional }\end{array}$ & $\begin{array}{l}\text { Hazards relating to poor support from the organisation or inap- } \\
\text { propriate organisational pressures, e.g. inadequate training, poor } \\
\text { organisational change management, etc. }\end{array}$ \\
\hline \multicolumn{2}{|c|}{$\begin{array}{l}\text { Environmen-Hazards relating to the environment, e.g. spills and leaks, envi- } \\
\text { tal ronmental noise, hazardous emissions, etc. }\end{array}$} \\
\hline Financial & $\begin{array}{l}\text { Hazards relating to finance, e.g. staff costs, contractor costs, } \\
\text { taxes, material availability, stock management }\end{array}$ \\
\hline $\begin{array}{l}\text { Project } \\
\text { Manage- } \\
\text { ment }\end{array}$ & $\begin{array}{l}\text { Hazards relating to projects, e.g. human resource availability, } \\
\text { project performance, stakeholder management, lifecycle man- } \\
\text { agement, contractor management }\end{array}$ \\
\hline
\end{tabular}

The interim development of the risk Register in the company took the shape of a SharePoint solution on the internal website of the company.

This interim solution was selected as it allowed a low cost internal development of a prototype to test the stability of the data structure proposed in view of channelling more advanced functional requirements for a web based application capable of supporting also the risk reporting and data analysis needs.

\subsection{Risk Management Process}

The risk management process around the Risk Register consists of three main parts:

1. Monthly Risk Update - at station level;

2. Quarterly Risk Validation - involving both station level and organisation-level risk specialists;

3. Quarterly Risk Reporting - at organisation and senior management level - involving Risk Reporting Managers and members of the Senior Management Team.

The process ensures that the report is fed back to station risk specialists by the Generation Risk Reporting Manager, so that the most up to date risk information is circulated evenly and retained within the organisation for subsequent re-use.

Several KPI have been identified to monitor the use and content of the risk register and these are reported in Table 3.

Table 3: KPI identified to monitor trial implementation of the Risk Register

\begin{tabular}{|c|c|c|c|}
\hline No & KPI & $\begin{array}{l}\text { Fre } \\
\text { q. }\end{array}$ & Definition \\
\hline 1 & $\begin{array}{l}\text { Percentage of } \\
\text { Risks Updated } \\
\text { in the Last } 90 \\
\text { Days }\end{array}$ & $\begin{array}{l}\text { Mont } \\
\text { hly }\end{array}$ & $\begin{array}{l}\text { Red: }<75 \% \text { of records updated; } \\
\text { Amber: }>75 \% \text { of records updated; } \\
\text { Green: } 90 \% \text { of records updated. }\end{array}$ \\
\hline 2 & $\begin{array}{l}\text { Average Mitiga- } \\
\text { tion Effective- } \\
\text { ness }\end{array}$ & $\begin{array}{l}\text { Mont } \\
\text { hly }\end{array}$ & $\begin{array}{l}\text { Red: score }<2 \\
\text { Amber: } 2<=\text { score }<4 \\
\text { Green: } 4<=\text { score }<=5\end{array}$ \\
\hline 3 & $\begin{array}{l}\text { Mitiga- } \\
\text { tion/Control } \\
\text { Measures in } \\
\text { Place and Func- } \\
\text { tioning (Audited) }\end{array}$ & $\begin{array}{l}\text { Quar } \\
\text { terly }\end{array}$ & $\begin{array}{l}\text { based on four risk management } \\
\text { audits completed in each station } \\
\text { annually to review control measure } \\
\text { application defined as a proportion } \\
\text { of satisfied audit requirements: } \\
\text { Red: less than } 75 \% \text {. } \\
\text { Amber: less than } 90 \% \\
\text { Green: } 90 \% \text { or more. }\end{array}$ \\
\hline 4 & $\begin{array}{l}\text { Number of Red } \\
\text { and Amber } \\
\text { Risks }\end{array}$ & $\begin{array}{l}\text { Mont } \\
\text { hly }\end{array}$ & $\begin{array}{l}\text { The focus is on the month-to- } \\
\text { month trend. }\end{array}$ \\
\hline 5 & Risk Decrease & $\begin{array}{l}\text { Quar } \\
\text { terly }\end{array}$ & $\begin{array}{l}\text { Percentage of risk entries against } \\
\text { which the risk exposure was actu- } \\
\text { ally decreased. }\end{array}$ \\
\hline
\end{tabular}

As part of the rollout, the stations were provided one to one training in the form of a face to face meeting or a teleconference on the new tool and asked to input their risk and during the first two quarters. Following this a risk review workshop was organized in each station to review their risk and collect feedback on the tool.

\subsection{Interim Evaluation}

The Register was evaluated to verify:

1. How well the data structure supports the identification and categorisation of risks;

2. How the rating scheme is used to manage and prioritise risks (facilitating the risk management process);

3. The attitude of the stations towards use of the final tool, (their willingness to populate data); 
4. The perceived effectiveness and efficiency of the tool across the different stakeholders;

5. Assessment against the high level requirements.

The feedback was collected in two ways:

A. A survey addressed to the users in each station in charge of reporting towards the generation risk register

B. The feedback collected at the annual risk review workshops held in each station during first quarter of 2014 and 2015.

The users evaluated the tool as useful and helpful to share risks and improve awareness, however the IT implementation itself was criticised as not being very user friendly. A brief overview of the results is reported in figure 2 .

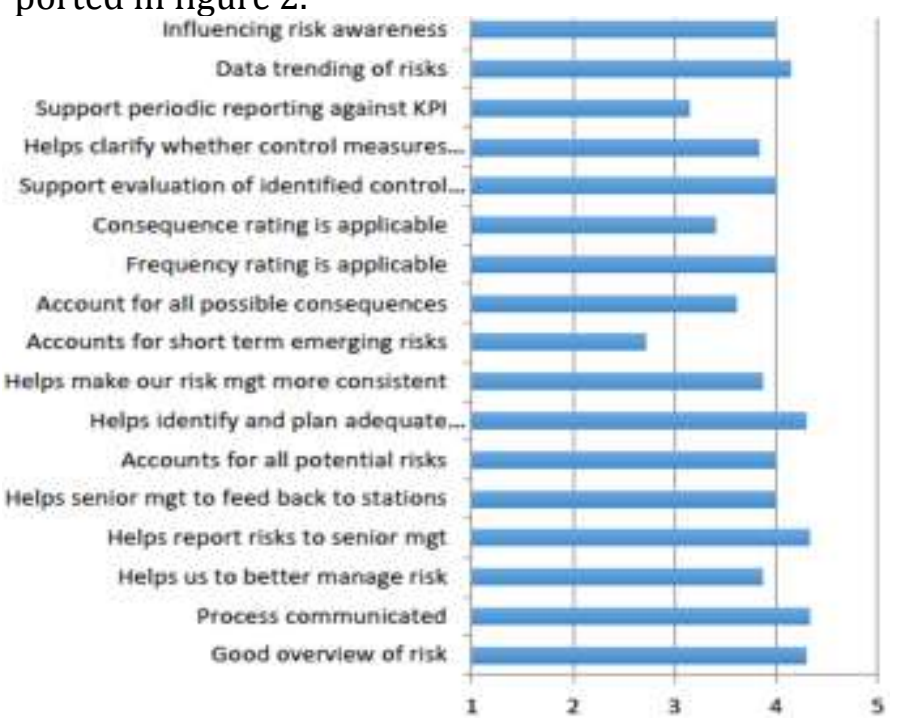

Figure 2: evaluation of questionnaire responses

\subsection{Feedback on Data Structures}

The data structure is able to provide a harmonised view of the main hazardous scenarios shared across the business in various stations (see figure 3 ).

\section{Root Causes in each Risk Centre}

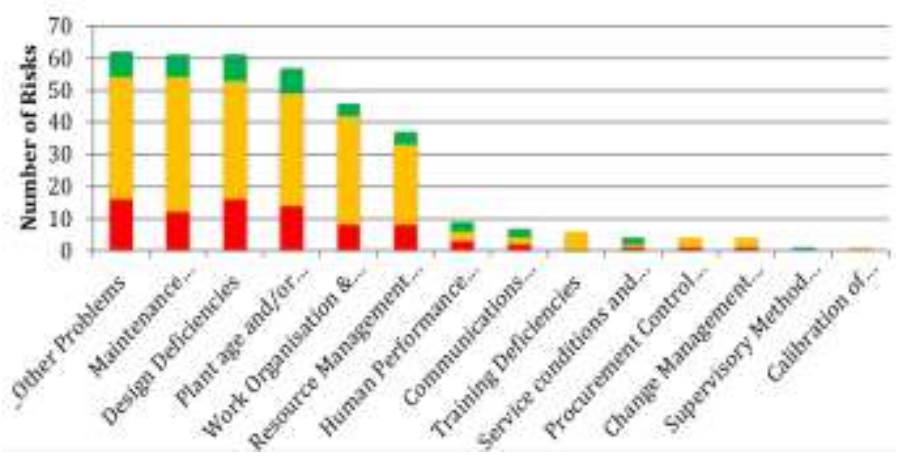

Figure 3: Common root causes for the hazards reported

A key finding from the implementation of the risk register is that the local business units cannot actively manage a fully comprehensive set of risks facing their area of the business, as these can quickly become overwhelming and the risk register becomes encumbered by low level risks that are routinely effectively managed through existing standards and procedures. The risk register should contain all risks being actively managed - those which require additional invest- ment or further analysis, and those which have a high degree of uncertainty associated with them. Low level risks or risks managed on an on-going basis through established business process will not benefit from the additional scrutiny of being on the risk register, and may serve to obscure more critical risks. However, the set of hazards should be as comprehensive as possible, in order to prompt entries and help with analysis of the data held in the register. Some flexibility in the hazard categories may be necessary to allow them to be adjusted and expanded according to business needs.

Empirical data might be collected over time through data mining accident and incident databases, as well as the risk register itself to support the assessment of likelihood or severity of foreseen risks. The rating is therefore currently very subjective, and even using a clearly defined scale one user may be inclined towards higher ratings than another. The differences may not be great (one point either direction), but on a five point scale this can make the difference between an amber rating (e.g. 12) or a red rating (e.g. 16). As well as the unintentional variability introduced through subjectivity, some business units might also intentionally increase their ratings to theoretically possible but unrealistic values in order to highlight an issue in their area and require investment to address it. It is therefore necessary to include a review step in the business process underlying the risk register. As issues emerge, additional guidance and modifications can be added to the scales to improve the reliability of the ratings, to help improve consistency.

\section{RISK REGISTER \& OPERATIONS}

\subsection{The process of top risk aggregation across stations}

The Risk Register in the case is still currently under a second stage of development as it is currently a system that generates a single large table of risks for the business. This approach allows for consistency of the register's data as all stations use the same set of column dropdown values, helping to structure their inputs and analysis. For simplicity, each risk is detailed in one complete record including categorisation, pre- and post- mitigation scoring and current and planned mitigating action. This system effectively serves its stated purpose however it needs an IT solution better able the following aspects:

1) Aggregation of entries from stations to central level;

2) Support controls over mitigation measures at station and central level;

3) Support data based estimates for likelihood of scenarios based on accident data;

4) Integration with company asset register;

5) Support workflow around risk communication; 
6) Link with day to day operational practice.

Each of these potential improvements are discussed in the following sections.

\subsection{Aggregation of risks to central level}

The rating scheme of the risks based on the risk matrix is currently used for the purpose of sorting and screening, while the risk register needs to include a further criteria to estimate corresponding classes of monetized risk values to be able to aggregate risks that are in common across multiple stations with different likelihood and exposure in the various impact categories. The risk matrix score is in fact provided on the basis of qualitative scales. Qualitative scales are themselves inherently flawed when it comes to aggregate risk. When using qualitative scales, it is very difficult to say how to compare 2 High risks with 3 Medium risks, or how high is a High risk. This is a primary motivation for trying to monetize rating scales. This will enable hazard categories to be sorted across different stations on the basis of sum of equivalence of economic value of impact multiplied by likelihood for each event category. The system can ultimately rank risks across equivalent economic ranges for Cat 1 (red) Cat 2 (orange) and Cat 3 (yellow) and Cat 4 (green). A trial implementation of this approach has been achieved in the case study organisation. Table 4 reports an example of the resulting aggregated Top Ten issues obtained using the monetized categories.

Table 4: Example of top 10 scenarios aggregated

\begin{tabular}{|c|c|c|c|c|c|}
\hline & hazard & types & at & central & \multirow{2}{*}{$\begin{array}{l}\text { leve } \\
\text { Max } \\
\text { Future } \\
\text { Exposure }\end{array}$} \\
\hline ref & top 10 scenartios & $\begin{array}{l}\text { Number of } \\
\text { afferted } \\
\text { centres }\end{array}$ & $\begin{array}{l}\text { Monetized } \\
\text { risk rlass }\end{array}$ & $\begin{array}{l}\text { Max } \\
\text { CURRENT } \\
\text { EXPOSURE. }\end{array}$ & \\
\hline 1 & $\begin{array}{l}\text { Ore Conditions } \\
\text { Inexperienced workers }\end{array}$ & 9 & Cat 1 & 10 & 12 \\
\hline 2 & Fin. - Plant performance & 12 & Cat 2 & 60 & 12 \\
\hline 3 & $\begin{array}{l}\text { Tech. - Mechanical integrity } \\
\text { \& design flaws }\end{array}$ & $y=12$ & Cat 2 & 15: & 12 \\
\hline 4 & Tech. - Aging & 11 & Cat 2 & 15 & 9 \\
\hline 5 & Tech-Rellabsilty & 12 & Cat 2 & 12 & 12. \\
\hline 6 & $\begin{array}{l}\text { External Safety - Adverse } \\
\text { weather }\end{array}$ & 8 & Cat 2 & & 10 \\
\hline 7 & Fin- Market & 12 & Cat 2 & 16 & 12 \\
\hline B & $\begin{array}{l}\text { Regulatory = Breach of } \\
\text { operating license }\end{array}$ & ${ }^{\circ}{ }_{8}$ & Cat 3 & & 9 \\
\hline 9 & $\begin{array}{l}\text { Regulatory - Civil } \\
\text { criminal litigation }\end{array}$ & & Cat 3 & & 1 \\
\hline 10. & Fire & 9 & Cat 3 & 12. & 10 \\
\hline
\end{tabular}

\subsubsection{Aggregation of risks for safety outcomes}

The tool can query all the events leading to possible fatality scenario and the initial assumption is that the overall probability of one fatality in the year is the sum of all the individual entries potentially leading to single or multiple fatalities can be considered together with their associated expected value of their likelihood range. If this sum leads to a likelihood above the max value assumed for category 3 in the likeli- hood scale in case of single fatality and above the values covered by categories 2 in the likelihood scale for multiple fatalities it is flagged to the management team as a companywide Red exposure and it triggers the need to intervene for the entries contributing towards that risk.

\subsection{Controls over mitigation measures}

A second issue that the introduction of the risk register in the organization brought to the fore is how can the tool better support the workflow connected with ensuring appropriate control measures are in place for each risk in each stations and how to share the knowledge about the most effective measures identified so as to foster reinforcement of best practices across different stations. Information on the effectiveness of mitigations is currently captured in a free text space and via a subjective rating. The documented mitigation measures are subsequently audited in each station through the internal risk management audit scheme (which foresees one internal audit to be carried out in each station quarterly). Currently a manual KPI is calculated based on the results of the four risk management audits completed in each station annually to review control measure application defined as a proportion of satisfied audit requirements. A proposed improvement in risk register would enable the tool to document and support the workflow connected with monitoring and reviewing mitigations.

\subsection{Likelihood and updates of events from acci- dent database}

The likelihood ratings are also currently subjective, and hence open to bias (either positive or negative). On the basis of the events collected in the accident and incident database of each station it may be possible to inform less subjective estimates for the likelihood ranges of the scenarios to be documented in the risk register. The company in this case study currently has a different IT system for documenting and classifying accidents and incidents. On the basis of the entries to this system, it is possible to estimate for each hazard category a corresponding rate based on the past six years of reporting history at company level, which in turn can provide the basis to estimate the average number of events per year and use that as a designated rate parameter $(\lambda)$ in a Poisson distribution. The system could automatically suggest the probability of observing $\mathrm{k}$ events in a year using the Poisson formula. To enable this functionality, the hazard categories collected in the existing accident and incident reporting tools and those used by the risk register will have to be harmonised. Table 5 re- 
ports a snapshot of some of the events that can be collected from the incident reporting systems.

Table 5: Example of incident data

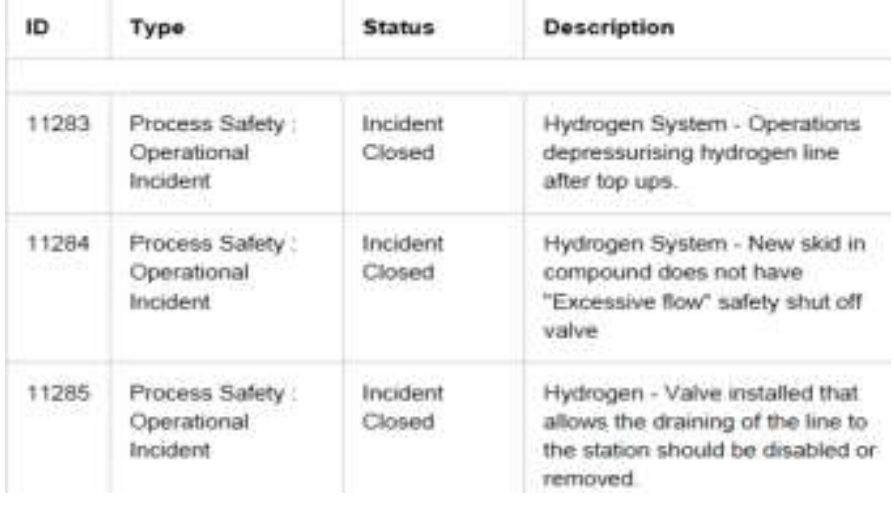

\subsection{Integration with Critical Asset Registers}

A component or system in the company is defined as Safety Critical if its function is to prevent an abnormal condition escalating into a major incident (ISO 55001 2014). To ensure best practice in terms of safe and efficient asset management the company adopted the industry standard PAS 55 issued by the Institute of Asset Management and published by the British Standards Institution in 2004(PAS 55:2008). The standard provides guidance across several aspects of good asset management, from lifecycle strategy to everyday maintenance. It was then transitioned to ISO 55000 an international standard covering management of physical assets. The company currently uses a common structured spreadsheet as a critical asset register (CAR) for all stations. The tool is held in a spreadsheet format stored in an integrated on line shared location, with a separate workbook for each station and accessible to central asset specialists. The tool reports the minimum required information for each station and calculates a risk rating for each based on the status, but it does not actually detail the failure modes and their consequences upon which the risk rating is based. The risk register fills this gap. If the CAR tool were to support a better identification of hazards associated to each piece of equipment in alignment with what is required by the risk register, the tool could in itself cover all the requirements to also serve the purpose of assert risk register for the company as a whole and for each station considering the technical asset risks. This in turn will lead to move also the current CAR towards a web based and integrated knowledge management IT solution that can be considered a module of the risk register.

\subsection{Support a better link with workflow around risk communication}

One of the main issues collected through the initial feedback is that the Risk Register tool as implement- ed in the case study did not fully support an actual engagement and two way communication loop between stations and central asset specialist and or stations and central management. Despite being a requirement from the outset, the ability to provide meaningful two-way communication is limited by the Sharepoint format, which is primarily a data repository. The Risk Register works more as a one-way communication whereby the stations communicate their risk centrally but do not receive any actual feedback or updates about possible central improvements or best practices around mitigation strategies for their risk and how they are managed or shared similarly elsewhere.

To be able to do so, a more powerful web-based IT solution could support the monthly and quarterly reporting/communication both at station level (from station to central location) but also from central level to station level, effectively supporting revisions of those risks by either asset specialist or by Management committee meeting.

\subsubsection{The link with day-to-day practice}

As part of the process safety improvement plan of the company there is an on-going effort to support consistent and efficient transfer of safety, operational and commercial information between operational shifts to reduce the potential for misunderstanding or the non-reporting of technical or commercial events, issues, status or risks though a computerised logging system to improve the management and communication of critical operating information connected to shift handovers. The scope is to achieve the following benefits:

1. Improved safety of personnel and plant

2. Improved environmental performance

3. Improved commercial performance

4. Standardisation of plant operation

5. Regulatory compliance

6. Reduction in duplicated reporting

7. Optimisation of existing processes.

In addition to the above improvements, Process Safety improvements will further require recording of operational abnormalities including: demand on safety systems, plant upsets, insufficient operating discipline, procedures not followed, near misses, etc. as lower tier incidents, which can be then be analysed and improved on. This can also lend itself to a way of improving a two way live feed between an operational $\log$ and the risk register as the risk register can provide an overview of the main company risk scenarios relevant for operations but on the other end the operational $\log$ can provide info to verify how those risks may actually affect operational practices 
and introduce new potential risks on the basis of observed deviations from recommended design ranges. The two systems would need to be able to exchange information automatically.

\section{CONCLUSIONS}

This paper has described the development and implementation of a shared Risk Register in an electricity generating business. The implementation has uncovered areas for future development that can improve risk management further. The considerations discussed in the previous section would suggest that the best way to further implement the knowledge management capacity of the risk register is by integrating new functions into the current IT system used in the company for accident incident and near miss reporting by providing a further elements for hazard identification (not retrospective in nature) and to follow up the risk review process and the monitoring (audit) for each station and at the same time facilitating the sharing of best practices and information across the multiple locations (as a web based application).

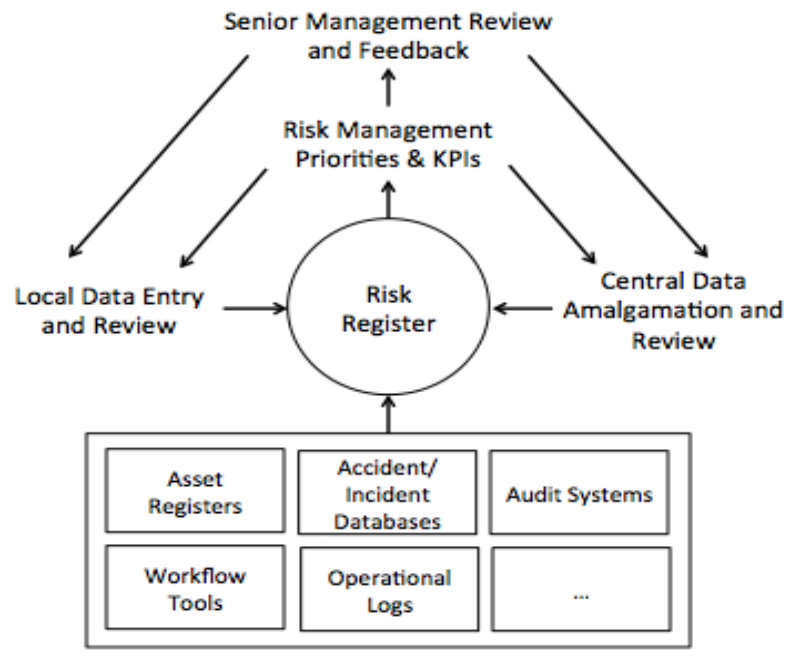

Figure 4: Agenda for Risk register integration into Process Safety Framework tools

The framework reported in Figure 4 describes a situation where existing systems containing relevant information (e.g. asset registers, incident databases, audit system, etc.) are linked to the risk register. Ideally this link would be automatic to reduce manual processing time and/or duplication of effort. This is the vision for the futures stages of development of the register to allow a more comprehensive and dynamic knowledge of company risks. This information must be reviewed and acted upon at both a local level, to ensure front line risk management, and at a central level to ensure company-wide measures for effective and efficient monitoring by senior management.

\section{Acknowledgements}

The authors wish to acknowledge the research grant from Science Foundation Ireland (SFI) under Grant Number 14/IFB/2718 and by the EU FP7 project 'Total Safety Management for Critical Activities' (TOSCA; see www.toscaproject.eu) under Grant Agreement FP7-NMP2012-SMALL-6-310201.

\section{References}

Balfe, N., Leva, M.C., McAleer, B. \& Rocke, M. 2014. Safety Risk Registers: Challenges and Guidance. Chemical Engineering Transactions, 36, pp. 571-576.

PAS 55:2008 Institute of Asset Management. Retrieved 20 February 2015.

Cooke-Davies, T. 2002. The "real" success factors on projects. International Journal of Project Management, 20, 185-190.

Cox L.A. 2008 What's Wrong with Risk Matrices?. Risk Analysis, Vol. 28, No. 2, 2008

Crossland R, McMhahon, CA, Simms Williams JH. 1998 Survey of current practices in managing design risk. Design Information Group, University of Bristol.

De Zoysa, S. Russell, A.D. 2003. Structuring of risk information to assist in knowledge-based identification of the life cycle risks of civil engineering projects. 5th Construction Speciality Conference of the Canadian Society for Civil Engineering, Moncton, Canada, 4-7 June, 2003.

Dunović, I.B., Radujković, M., \& Vukomanović, 2013. Risk register development and implementation for construction projects. Gradevinar, 65, 1, 23-35.

Filippin, K. Dreher, L. 2004. Major hazard risk assessment for existing facilities. Process Safety Progress, 23, 4, 237-243.

Hasle, J.R., Kjellen, U., \& Haugerud, O. 2009. Decision on oil and gas exploration in an Arctic area: Case study from the Norwegian Barents Sea. Safety Science, 47, 832-842.

ISO 55001:2004 Asset Management. BSI Group.

ISO 17776. 2002. Petroleum and natural gas industries - Offshore production installations - Guidelines on tools and techniques for hazard identification and risk assessment. International Organisation for Standardisation: Geneva.

Kontogiannis, T., Leva, M.C., \& Balfe, N. (this issue). Total Safety Management: Principles, processes and methods.

Leonard, J.B. 1995. Assessing risk systematically. Risk Management, 42, 1, 12-17.

Leva M.C., Pirani R., De Michaela M., Clancy P., 2012, Human Factors Issues and the Risk of High Voltage Equipment: Are Standards Sufficient to Ensure Safety by Design?, Chemical Engineering Transactions, 26, 273-278

Leva, M.C., Balfe, N., Kontigiannis, T., Plot, E., Demichela, M. 2014. Total Safety Management: What are the main areas of concern in the integration of best available methods \& tools. Chemical Engineering Transactions, 36, 559-564.

MIL-STD-882E, Standard Practice for System Safety, 2012

Monferini, A., Konstandinidou, M., Nivolianitou, Z., Weber, S., Kontogiannis, T., Kafka, P., Leva M.C., Demichela, M. (2013). A compound methodology to assess the impact of human and organizational factors impact on the risk level of hazardous industrial plants. Reliability Engineering \& System Safety, 119, 280-289.

Patterson, F.D., \& Neailey, K. (2002). A risk register database system to aid the management of project risk. International Journal of Project Management, 20, 365-374.

Reason, J. (1997). Managing the risks of organisational accidents. Aldershot: Ashgate.

Whipple T., Pitblado R., 2010. Applied risk-based process safety: A consolidated risk register and focus on risk communication. Process Safety Progress, 29, 1, 39-46. 